Corrigendum

\title{
Corrigendum to "A Rare Presentation of Cardiac Tamponade from Metastatic Urothelial Carcinoma of the Bladder"
}

\author{
Sowmya Palam $\mathbb{D}^{1},{ }^{1}$ Ridhima Kapoor, ${ }^{1}$ Amrou Abdelkader, ${ }^{2}$ and Jacquelyn Kulinski ${ }^{1}$ \\ ${ }^{1}$ Department of Internal Medicine, Medical College of Wisconsin, 9200 W. Wisconsin Ave., Suite 5100, Milwaukee, WI 53226, USA \\ ${ }^{2}$ Medical College of Wisconsin Department of Pathology, USA \\ Correspondence should be addressed to Sowmya Palam; spalam@mcw.edu \\ Received 3 July 2019; Accepted 9 August 2019; Published 12 September 2019 \\ Copyright ( 2019 Sowmya Palam et al. This is an open access article distributed under the Creative Commons Attribution License, \\ which permits unrestricted use, distribution, and reproduction in any medium, provided the original work is properly cited.
}

In the article titled "A Rare Presentation of Cardiac Tamponade from Metastatic Urothelial Carcinoma of the Bladder" [1], Dr. Amrou Abdelkader was missing from the authors' list. Dr. Amrou Abdelkader was involved in writing and editing the pathology portion of the article and providing the pathology photos (Figures $3(\mathrm{a})-3(\mathrm{~d})$ ) and the associated legend. The corrected authors' list is shown above.

\section{References}

[1] S. Palam, R. Kapoor, and J. Kulinski, "A rare presentation of cardiac tamponade from metastatic urothelial carcinoma of the bladder," Case Reports in Cardiology, vol. 2018, Article ID 6750264, 4 pages, 2018. 


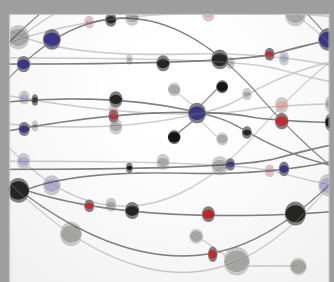

The Scientific World Journal
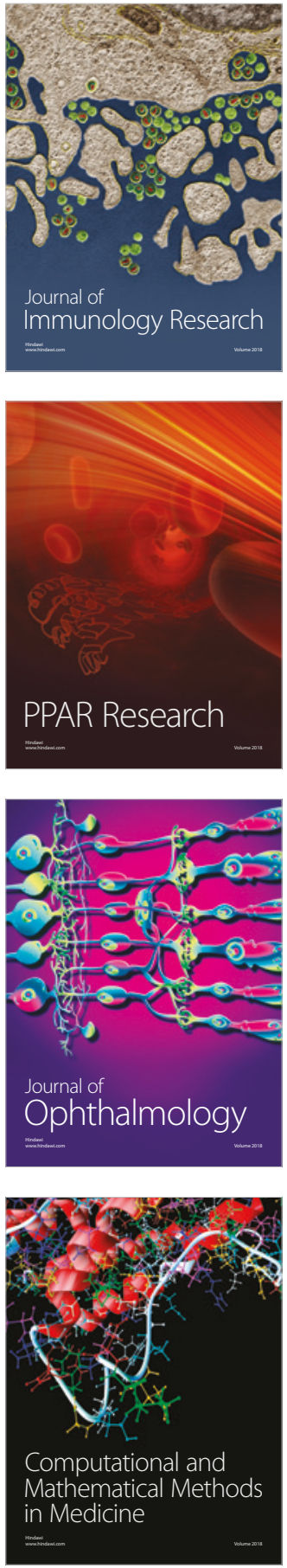

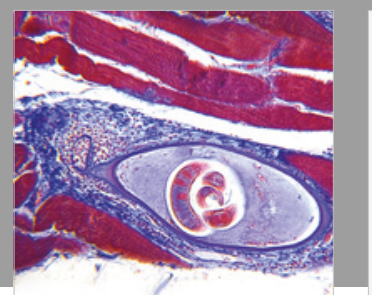

Gastroenterology Research and Practice

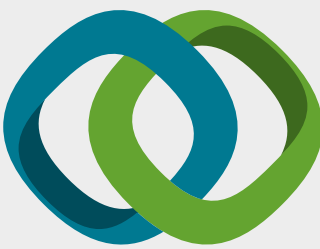

\section{Hindawi}

Submit your manuscripts at

www.hindawi.com
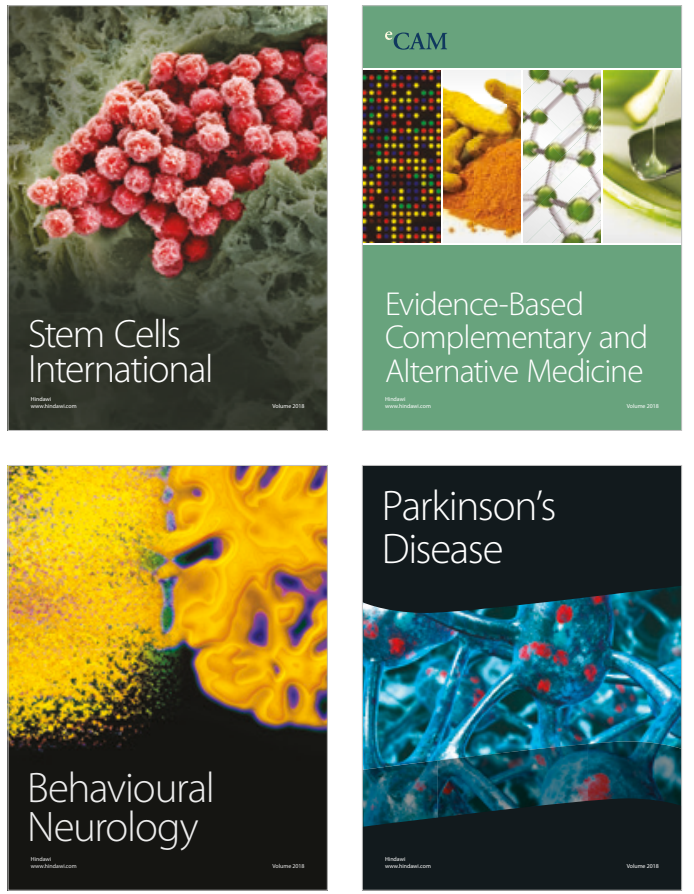

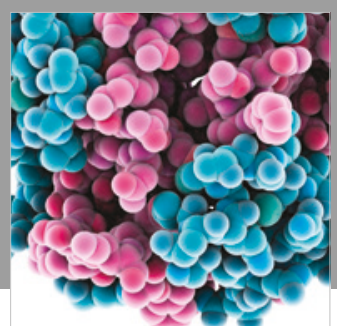

ournal of

Diabetes Research

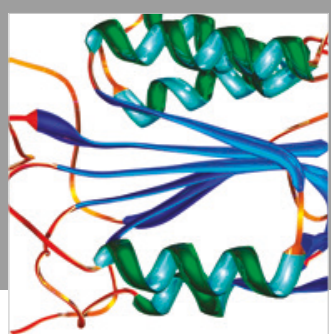

Disease Markers
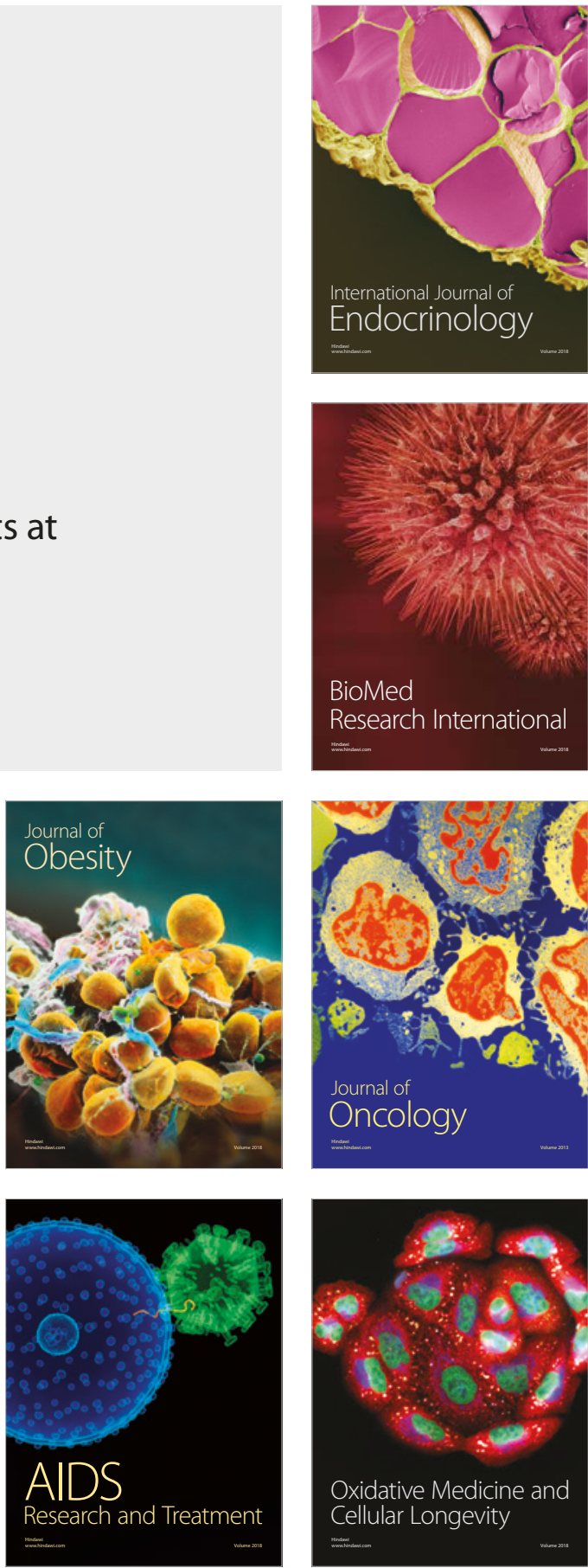